\title{
RELAÇÕES SEM COMPROMISSO ENTRE ADOLESCENTES
}

José Roberto da Silva Brêtas ${ }^{1}$; Silvia Piedade de Moraes²; Luiz Fabiano Zanatta3; Maria José Dias de Freitas ; Ana Maria Limeira de Godoi ${ }^{5}$; Lais de Souza Ricardo ${ }^{6}$

\section{RELATIONS WITHOUT COMMITMENT AMONG TEENS}

Resumo: Este estudo teve como objetivo identificar o que pensam os adolescentes do sexo masculino e feminino sobre relações sem compromisso. A pesquisa de natureza qualitativa foi realizada com 750 adolescentes entre 12 e 18 anos de idade (324/43\% do sexo masculino e $426 / 57 \%$ feminino) e desenvolvida em três escolas de ensino fundamental e médio da região de Santo Eduardo do município de Embu das Artes, São Paulo. Os resultados possibilitaram desvelar categorias como: qualificações das relações sem compromisso; estigmatização; experiências passageiras; consequências das relações sem compromisso. Concluiu-se que as relações sem compromisso entre adolescentes propiciam a vivência da sexualidade, possibilitam a oportunidade de estabelecimento de relacionamentos amorosos que podem ser considerados eventuais ou duradouros. Trata-se de um comportamento de risco que merece atenção dos profissionais das áreas de saúde e educação, com ações educativas voltadas para educação em saúde.

Palavras-chave: adolescente; comportamento sexual; gênero; sexualidade

\begin{abstract}
This study was intended to identify what they think teens of the masculine and feminine sex on the act of relations without commitment. Qualitative Research carried through with 750 adolescents between 12 and 18 years of age (324/43\% of the masculine sex and $426 / 57 \%$ feminine). It was developed in three schools of basic and average education in Santo Eduardo, region of the Embu of Arts city, São Paulo. The results made it possible to reveal categories such as: qualifications of relations without commitment; stigmatization; experiences passengers; consequences of relations without commitment. The relationship between adolescents without compromise provides the experience of sexuality, enables the opportunity of establishing romantic relationships that can be as casual or long lasting. It is a risky behavior that deserves attention of professionals in the health and education areas, with educational actions for health education. Keywords: adolescent; sexual behavior; gender; sexuality
\end{abstract}

1Psicólogo. Professor associado da Universidade Federal de São Paulo - Unifesp. E-mail: bretas@ymail.com/jrsbretas@gmail.com 2Pedagoga. Coordenadora de programas educacionais da prefeitura de Guarulhos, SP. Doutoranda em Ciências pela Unifesp. Membro da SBRASH.

${ }^{3}$ Enfermeiro. Professor da Universidade Estadual do Norte do Paraná - UENP. Doutorando em Ciências pela Unifesp.

${ }^{4}$ Pedagoga. Professora da Universidade Paulista - UNIP. Doutoranda em Ciências pela Unifesp.

${ }^{5}$ Enfermeira do Instituto do Coração do Hospital das Clínicas da Faculdade de Medicina da Universidade de São Paulo. Mestranda em Ciências pela Unifesp.

${ }^{6}$ Enfermeira do Hospital Israelita Albert Einstein. Mestranda em Ciências pela Unifesp. 


\section{Introdução}

$\mathrm{Na}$ adolescência o indivíduo passa por intenso crescimento e desenvolvimento que se manifesta por marcantes transformações anatômicas, fisiológicas, psicológicas e sociais, em um determinado contexto sociohistórico. As mudanças corporais e a sexualidade são, sobretudo, elementos estruturadores da identidade do adolescente. Essa função estruturante é, em grande parte, realizada por meio da representação mental que o adolescente tem de seu corpo, de sua imagem corporal (BRÊTAS; MUROYA; GOELLNER, 2009).

A sexualidade é algo que se constrói e aprende, sendo parte integrante do desenvolvimento da personalidade, capaz de interferir no processo de aprendizagem, na saúde mental e física do indivíduo.

Há também uma transformação na convivência social, em que o adolescente começa a se relacionar com turmas e a exercitar sua possibilidade de relacionamento com os outros. Como em os outros momentos da vida do adolescente, enfrentar essa nova situação desperta medo e receio, ao mesmo tempo em que há o interesse em conhecer e buscar o novo (BRÊTAS et al., 2011).

É nessa época que começa a haver o interesse pelas relações afetivas e sexuais. $\mathrm{O}$ namoro tem uma função clara de aprendizado da sexualidade e interação afetiva e, na atualidade, também tem sido uma forma de relação afetiva e/ou sexual sem envolvimento de compromissos. Esse fenômeno cultural de maior flexibilidade nos relacionamentos tem sido denominado "ficar" ou "pegar" (OLIVEIRA; GOMES; MARQUES, 2007).

Como resultado da cultura e de uma história das mentalidades, as diferentes formas de interação afetiva passam por mudanças. Na década de 1980 o termo "amizade colorida" significava que entre grupos de amizades havia também encontros afetivos e sexuais sem quaisquer compromissos. Na década de 1990, há uma ampliação na ideia de estar com alguém (afetiva e sexualmente) sem que houvesse qualquer compromisso. As fronteiras dos círculos de amizade são rompidas e passam a comportar qualquer pessoa pela qual se tem interesse mútuo. Assim, "ficar" e "pegar" tornaram-se não somente práticas da vida afetivo-sexual de adultos quanto chegou e permanece crescendo entre adolescentes (JESUS, 2005).

Essa busca por prazer constitui-se em importante forma de aprendizado social, afetivo e sensorial, iniciando-se geralmente entre 12 e 14 anos de idade. Posteriormente, cada pessoa pode, sem que haja uma idade pré-determinada, adotar outras formas de relacionamentos mais estáveis (CASTRO; ABRAMOVAY; SILVA, 2004).

Atualmente estão difundidos entre os adolescentes, jovens e também adultos, os aplicativos para smartphone nos quais o objetivo é conhecer pessoas em busca de uma saída casual, sexual, relacionamento sério, amizade etc. São vários os aplicativos, como Tinder, Badoo, Kickoff, Happn, Hot or not entre outros que usam a geolocalização. Como se fosse um menu ou álbum de figurinhas, o usuário analisa perfis daqueles que estão próximos (ou em até um raio de $160 \mathrm{~km}$ de distância, dependendo do aplicativo) e seleciona quais são de seu interesse. Se houver interesse mútuo, duas pessoas podem entrar em contato e assim marcar um encontro. Geralmente esses aplicativos estão conectados ao Facebook ou a uma conta no Google. No perfil da pessoa aparece em qual distância está, idade, algumas fotos e interesses pessoais.

Segundo um estudo realizado por Oliveira, Gomes e Marques (2007), sobre representações do "pegar", "ficar" e "namorar", os resultados indicaram várias formas de relacionamentos entre os adolescentes. Estas são classificadas em um continuum que vai da liberdade absoluta à responsabilidade formalizada de forma que não possuam relação somente com a outra pessoa envolvida (parceira/parceiro), mas incluem suas famílias e os grupos sociais em que esses adolescentes se inserem. Essas formas de relacionamento também têm estreita relação com a descoberta do corpo do outro e a intensidade que esse corpo produz no adolescente.

Ainda não há clareza sobre os impactos que a experiência do "ficar" associada ao uso de aplicativos pode ter sobre a vida dos adolescentes. No que diz respeito aos antigos padrões comportamentais (de pressionar meninos a se comportarem de forma machista e de julgamento moral do comportamento sexual e afetivo das meninas) foi uma importante conquista da juventude. $\mathrm{O}$ que pouco se sabe é se os impactos na saúde, na integridade física e emocional têm sido também positivos.

Considerando a complexidade do assunto sobre o comportamento sexual do adolescente, construímos um projeto envolvendo a temática da sexualidade e prevenção, com ênfase no comportamento preventivo dos adolescentes. $O$ presente estudo teve como objetivo conhecer o que pensam adolescentes e jovens sobre o comportamento de relacionar-se sem comprometimento social ou afetivo e identificar as subjetividades decorrentes desta prática na perspectiva da categoria analítica gênero. 


\section{Método}

Trata-se de um estudo descritivo com abordagem qualitativa, em que utilizamos o método da Análise de Conteúdo, que pode ser definida como um conjunto de técnicas de análise de comunicação visando obter, por procedimentos sistemáticos e objetivos de descrição do conteúdo das mensagens, indicadores que permitem a inferência de conhecimentos relativos às condições de produção/ recepção das mensagens. Utilizou-se para análise de conteúdo a técnica denominada Análise Categorial que proporcionou o desmembramento do texto em unidades, em categorias segundo reagrupamentos analógicos (BARDIN, 2010).

O projeto deste estudo foi avaliado e aprovado pelo comitê de ética da Universidade Federal de São Paulo (UNIFESP) com protocolo n. 1404/11, obedecendo todos os padrões estabelecidos pela resolução 466/12, que trata das normas de pesquisa envolvendo seres humanos (BRASIL, 2013). Destaca-se que os termos de consentimento e assentimento foram devidamente esclarecidos e assinados respectivamente pelos responsáveis e participantes do estudo.

Participaram do estudo 750 adolescentes entre 12 e 18 anos de idade (324 rapazes e 426 garotas) que frequentavam as atividades de educação em sexualidade desenvolvidas pelo projeto de extensão universitária "Corporalidade e Saúde", junto a três escolas de ensino fundamental e médio da região de Santo Eduardo, do município de Embu das Artes, São Paulo. Os critérios de inclusão dos participantes foram estar matriculados em uma das três escolas da região de Santo Eduardo e participar das atividades educativas do projeto de extensão universitária.

A coleta de dados ocorreu entre o período de outubro de 2011 e novembro de 2012 com uma questão norteadora aplicada em 15 grupos de adolescentes no período das referidas atividades, com o seguinte enunciado: "o que você pensa sobre a relação sem compromisso entre adolescentes?".

Após a coleta de dados, optamos pela análise categorial do universo "relação sem compromisso entre adolescentes", que se baseou na definição de categorias elaboradas a partir das narrativas dos adolescentes. Realizou-se a análise dos dados fazendo uma leitura integral das narrativas de cada participante tentando compreender as suas experiências. Foram lidos de tal forma a obter-se um sentido geral de todos os relatos. Em seguida, a releitura de cada relato buscou o significado da questão para cada participante. Os significados foram agrupados por suas semelhanças dando origem às categorias. Nesse sentido, Bardin (2010) refere que a categorização é uma operação de elementos construtivos de um conjunto, por diferenciação e, seguidamente, por reagrupamento de gênero (analogia), com os critérios previamente definidos. As categorias são rubricas ou classes, as quais reúnem um grupo de elementos sob um título genérico, agrupamento esse efetuado em razão dos caracteres comuns destes elementos.

\section{Resultados}

Com a estruturação em categorias, buscou-se contornos do sistema de significação que, no seu conjunto, revelaram a percepção dos participantes sobre o tema relação sem compromisso, que foram organizadas e apresentadas da seguinte maneira:

\section{Qualificações das relações sem compromisso}

A categoria mostrou, de forma geral, que as opiniões de garotas e rapazes foram semelhantes. As narrativas demonstraram que a relação sem compromisso envolve a concretização do ato sexual, como vemos:

É sexo. (rapazes, garotas)

É quando duas pessoas mantêm algum tipo de relacionamento sexual. (rapazes, garotas)

É apenas atração física. (garotas)

As narrativas mostram que garotas e rapazes apresentavam conotações de aprovação como uma manifestação do desejo, algo que todo mundo gosta, divertimento, algo agradável quando existe reciprocidade e como forma de conhecer pessoas.

É tudo de bom com quem a gente gosta mesmo. (rapazes, garotas)

Ficar com todos só para se mostrar ou outras coisas assim. Isso para alguns é só divertimento. (rapazes, garotas). garotas)

É uma coisa que todo mundo gosta. (rapazes,

Apontam, também, conotações de reprovação como algo sem sentido, sem caráter e algo que agride emocionalmente e imoral.

Sair pegando é uma coisa sem sentido. (garotas)

Ficar ou pegar alguém é uma pouca vergonha, é uma coisa para quem não tem caráter. (rapazes, garotas) 
Pra alguns é apenas curtir o momento machucando o outro. (rapazes)

Ficar é um modo de conhecer melhor a pessoa, só que é um modo diferente de fazer amizade. (rapazes, garotas)

É muito ruim, pois o que adianta beijar uma pessoa que a gente não ama, só fica para dar um beijo quando amanhã nem olha no rosto de quem ficou. (rapazes, garotas)

Os adolescentes apresentaram um campo de experiências para um relacionamento mais duradouro, como o namoro. As unidades significativas ocorreram tanto nas falas dos rapazes quanto das garotas, como vemos nas narrativas:

tas)

É um sentimento de carinho. (rapazes, garo-

É poder conhecer melhor a pessoa que futuramente pode ser seu namorado/a. (rapazes, garotas)

Pode durar um dia, dois, três dias, uma semana, ou às vezes durar muito tempo se transformando em namoro. (rapazes, garotas)

Eu entendo que ficar pode ser encarado como um novo amor ou um começo de um namoro sério. (rapazes)

\section{Estigmatização}

Esta categoria desvelou a tendência que os rapazes têm em rotular com conotações depreciativas as garotas que se relacionam com mais de uma pessoa em um mesmo lugar, por outro lado, as garotas demonstraram medo de serem estigmatizadas e expressaram cautela na seleção dos parceiros, como observamos nas narrativas:

As meninas que ficam com os meninos são todas galinhas. (rapazes)

Devemos ter consciência para depois não sofrermos com as consequências, como ficar mal falada. (garotas)

Muitas vezes é bom, mas as pessoas levam para a prostituição. (rapazes)

Não é só por que eu sou adolescente é que vou passar na mão de um e de outro. Tenho que valorizar meu corpo e o meu nome. (garotas)

\section{Experiências passageiras}

Esta categoria desvelou que este tipo de relação é na prática dos adolescentes um ato fugaz, passageiro, sem durabilidade e continuidade e, ao mesmo tempo, o que lhe dá consistência é, no dizer dos adolescentes, uma relação sem compromisso.

Relacionamento com alguém sem ter nenhum compromisso com ela, não precisando dar satisfações depois. (rapazes, garotas)

Pegar alguém é uma diversão passageira, um passatempo. (rapazes, garotas)

É quando você passa momentos e carícias com uma pessoa que você gosta ou tem atração, mas não é nada sério. (rapazes, garotas)

É um modo de conhecer o seu parceiro sem compromisso. (rapazes, garotas)

Passar apenas um momento gostoso com quem se está a fim. (garotas)

\section{Consequências das relações sem compromisso}

A categoria mostrou que os participantes acreditam que esse comportamento pode oferecer riscos para saúde dos/as praticantes.

As pessoas só pensam no prazer imediato, sem pensar na possibilidade de risco algum. (garotas)

Às vezes é bom e às vezes é ruim, porque podemos pegar doenças. (rapazes)

É por causa do ficar que está havendo muita gravidez de adolescentes. (garotas)

Ficar é tudo, no domingo que passou fiquei com uma menina e transamos sem camisinha, agora estou com um pouco de medo. (rapazes)

Acho que esse tal de ficar não é certo, pois uma pessoa pode estar contaminada e fica com outra, a outra fica com outra, assim vai passando a doença para outras pessoas. Assim, o portador não sabe e vai contaminando outras pessoas. (garotas, rapazes)

\section{Discussão}

Para os participantes da pesquisa, as relações sem compromisso são carregadas de julgamento de valor repleto de contradições. Tanto para as garotas quanto para os rapazes os princípios são muito semelhantes. As narrativas mostraram que garotas e rapazes apresentavam conotações positivas associadas à manifestação do desejo, à diversão e à ampliação nas relações e interações sociais. Destacaram como aspectos negativos a futilidade e a fragilidade que os vínculos afetivos e sociais podem ganhar criando relações sem sentido ou estabelecendo para si um caráter duvidoso. Além disso, destacaram que tais relações podem agredir emo- 
cionalmente e tornar-se imoral. Tais atribuições de valores deram-se possivelmente mediante as influências da família, religião e cultura de cada adolescente e das representações discursivas de condutas afetivas e sexuais muito presentes na sociedade.

Como destaca Jesus (2005), a relação sem compromisso é uma manifestação cultural. Neste sentido, Heilborn (2006) refere que a cultura é a responsável pela transformação dos corpos em entidades sexuadas e socializadas, por intermédio de redes de significados que abarcam categorizações de gênero, de orientação sexual, de escolha de parceiros. Valores e práticas sociais modelam, orientam e esculpem desejos e modos de viver a sexualidade, dando origens a carreiras sexuais/ amorosas.

As narrativas referem que os jovens só ficam com alguém por sentirem atração física, fato também relatado em um estudo realizado por Jesus (2005), no qual percebeu que a principal razão que leva uma pessoa a ficar com outra é a aparência física. Há uma supervalorização da imagem corporal pelos adolescentes, pois há influência de uma sociedade de consumo, capitalista, em que eles se preocupam em andar vestidos conforme a moda e os padrões de beleza são mais relevantes do que o próprio indivíduo.

Além de ser considerado por muitos uma novidade dos tempos modernos, podemos conjecturar que o comportamento de relação sem compromisso está desestabilizando tradicionais relações hierárquicas de gênero, desta forma, possibilitando que as jovens experimentem outras formas de vivenciar prazeres e afetividades, não necessariamente esgotando-se num significado único e libertário na prática da relação sem compromisso (CASTRO; ABRAMOVAY; SILVA, 2004).

Mesmo que esse e outros estudos mostrem que o comportamento das jovens está sob constantes controle e julgamento dos seus colegas, na atualidade discute-se a exigência de uma maior igualdade de direitos entre mulheres e homens. Essas novas formas de relacionamentos criam uma autonomia individual, mas que trazem em si resistências de uma cultura patriarcal opressiva às muIheres, tornando-as alvo constante de uma violência misógina e sexista (BORGES; NAKAMURA, 2009).

O "ficar" ou "pegar" pode ou não estar relacionado a práticas sexuais. Não há nenhuma garantia de relacionamento compromissado. Para muitos adolescentes é uma forma de conhecer antes de estabelecer um namoro. Esse acontecimento, por ser um relacionamento eventual, é uma forma de viver um intenso momento de descobertas sexuais, no qual ainda não se deseja um compromisso com muitas exigências (PAIVA, 1991).

No namoro, quer seja precedido ou não pelo "ficar", questões como a fidelidade se tornam importantes. É no decorrer do namoro, na medida em que a relação se firma, os jovens vão fortalecendo o afeto, atração mútua e o planejamento de ações conjuntas.

No caso do "ficar", os participantes da pesquisa declararam que as relações sem compromisso são percebidas como positivas para ambos os sexos, no entanto, para as meninas há um sutil código rígido que reverbera na qualificação de sua conduta moral - a garota não pode ficar no mesmo dia e mesmo local com dois ou mais garotos diferentes, caso contrário, receberá apelidos e nomenclaturas de desvalor à sua integridade.

Assim, se quanto ao conhecimento e ao aprendizado das interações afetivas e sexuais garotas e rapazes estejam muito próximos da igualdade, a variação das parcerias ainda responde a princípios patriarcais e machistas às mulheres. Há um sistema de valores e crenças generificados que ainda perduram, destacando as desigualdades entre a vida sexual das mulheres e a dos homens.

Para as garotas é como se um intervalo entre uma e outra "ficada" precisasse existir para restaurar "sua dignidade" perante o grupo social. Para os adolescentes, o sentimento de pertencimento em grupo é fundamental (BRÊTAS et al, 2011) e, por isso, crenças no interior do grupo podem pressionar seus membros a padronizar condutas. Desrespeitar regras de tamanha subjetividade não é fácil, visto que significa romper com aquilo que certamente também acredita para si e para o outro. Além do mais, o exercício de dizer "não" aos pares pode representar a aceitação de um estigma e a fragilidade dos vínculos de amizade.

Para as meninas o estigma negativo tem um peso ainda maior. Ao adquirirem determinadas famas, são ao mesmo tempo menosprezadas e pressionadas a realizarem o que não querem, colocando-as em situação de maior vulnerabilidade.

Com relação a essa forma de relacionamento, os jovens assumem uma atitude contraditória, no sentido de julgar o próprio comportamento; ao mesmo tempo que os meninos recriminam a alternância das garotas por ficarem com vários rapazes, são movidos por uma "competição" com o objetivo de se relacionar com o maior número possível de garotas (SOUZA; NUNES; MACHADO, 2012).

A relação sem compromisso na adolescência mostra uma representação do papel ativo que é atribuído ao homem e a necessidade de manter essa imagem. Esse fenômeno é reforçado pelas 
adolescentes do sexo feminino. Assim, a representação imagética de "fácil" ainda se encontra presente na cartografia mental feminina, assim como o encargo de se responsabilizar por medidas e tecnologias para a prevenção de doenças sexualmente transmissíveis e de gravidez. Esse fato deixa transparecer uma representação masculina de que a muIher é responsável pela preparação da cena em que o homem é convidado a atuar (OLIVEIRA; GOMES; MARQUES, 2007).

Segundo Connell (1995) existe uma narrativa convencional sobre como as masculinidades são construídas com uma definição das condutas e dos sentimentos apropriados para homens. Neste contexto, os rapazes são educados a agir e a sentir de forma característica e a se distanciar do comportamento das mulheres, das garotas e da feminilidade, compreendidos como o oposto. Grande parte dos jovens internaliza essa norma social e adota maneiras e interesses masculinos, frequentemente tendo como ônus a repressão dos seus sentimentos, o que pode levar à violência ou a dificuldades nas relações afetivas.

O projeto da masculinidade se revela (CONNEL,1995) quando a mesma valoração é aplicada a um rapaz. A variação de parcerias perde o sentido pejorativo e pode significar aquele que consegue seduzir, conquistar e finalmente "pegar" um grande número de garotas sempre que quiser. Este tipo acaba ganhando status junto ao seu grupo e incentivando outros que se identificam com sua maneira de agir. Há, assim, extremo destaque relacionando variação de parcerias à virilidade.

A ordem social masculina está tão profundamente arraigada que não requer justificação: se impõe a si mesma como autoevidente e é considerada "natural" devido ao acordo quase perfeito e imediato que obtém de estruturas sociais tais como a organização social do espaço e do tempo e a divisão social do trabalho, e, por outro lado, de estruturas cognitivas inscritas nos corpos e nas mentes (LAMAS, 2000).

Bourdieu (2011) refere que a dominação masculina está ancorada em nossos inconscientes, nas estruturas simbólicas e nas instituições da sociedade.

Assim, na busca da identidade masculina, a virgindade é vista como vergonha e o medo de demonstrar a falta de experiência faz com que o adolescente não se exponha perante o seu grupo. Além da necessidade de valorização da virilidade masculina, os adolescentes demonstram que a noção de masculinidade é fundada a partir da sociedade patriarcal, que ainda está presente na vida do adolescente atual e é reiterada pelas tradicionais expectativas das relações de gênero, ainda vigentes (BRÊTAS et al, 2011).

Atualmente, em nossa sociedade, uma das características mais evidentes da masculinidade é a heterossexualidade (BRÊTAS et al, 2011). O garoto busca sua masculinidade no lado oposto da feminização, ou seja, em oposição à mulher. Para Badinter (1993), a criança transforma sua primitiva identidade feminina em uma identidade masculina. No sistema patriarcal, os homens utilizam diferentes métodos para conseguir fazer do jovem, por sua vez, um "homem de verdade".

Nesse sentido, a valorização da primeira relação sexual pelo adolescente do sexo masculino existe em função da necessidade de se impor perante o grupo de amigos, sendo muitas vezes valorizado pela família, consistindo um rito de passagem (BRÊTAS et al, 2008), um marco importante na vida de um rapaz, no sentido de afirmar seu poder de "macho", traço ainda marcante da antiga identidade masculina. Não ter relações sexuais pode significar para o rapaz não demonstrar esse poder que pode estar associado à condição de escolha pela homossexualidade, uma grande preocupação entre adolescentes. Essa incursão, exercício do poder e autoafirmação da imagem de "macho" muitas vezes acontece de maneira agressiva, transgredindo o bom senso e as regras sociais, como observamos na narrativa.

É importante ressaltar que nessa prática encontra-se exemplificada a perpetuação da relação existente entre gênero e poder, presente no discurso de Foucault (2014) sobre a sexualidade. A construção cotidiana do domínio masculino sobre o seu corpo, em detrimento ao da mulher, define claramente os conteúdos do ser masculino e feminino que estruturam o duplo padrão de moral de nossa sociedade; o primeiro apresentando um caráter ativo, frente ao segundo, relacionado à passividade.

Nos discursos dos jovens esse comportamento configurou-se de certa forma como a interação afetiva e sexual em que se pode lidar com as demandas referentes às relações de namoro, consideradas mais rígidas. Neste sentido, a relação sem compromisso aparece como uma forma alternativa ao namorar, cujos aspectos mais enfatizados por rapazes e garotas dizem respeito ao relaxamento dos acordos mais complexos, pertinentes às relações estáveis. Assim, a obrigação da fidelidade é uma das dificuldades que o ficar minimiza, proporcionando maior flexibilidade das interações afetivas (CASTRO; ABRAMOVAY; SILVA, 2004).

As narrativas delimitadas e apresentadas na 
categoria "experiências passageiras" indicaram que esse tipo de interação traz para os jovens certa descontração no que se refere aos códigos estabelecidos para as relações de namoro.

Os dados desta categoria permitiram a correlação com o anterior, em que a expressão "estar com duas garotas ou mais" reforça a estigmatização masculina em relação às garotas. Já a unidade significativa "passar apenas um momento gostoso com quem se está afim" contribuiu com a precaução das garotas na autovalorização.

As garotas demonstraram preocupação com a gravidez, enquanto os rapazes revelaram preocupação com DST. Essa constatação pode ter relação com o fato de que os rapazes apresentem dificuldade em aceitar o uso da camisinha e as garotas apresentam dificuldade em argumentar a necessidade do uso.

Trata-se do fator cultural, em que adolescentes relataram que o uso da camisinha atrapalha o prazer do ato sexual, sendo expressa popularmente na conhecida frase "chupar bala com papel". Esta conotação dada à camisinha está diretamente ligada à própria noção de masculinidade que ainda permeia parte da cultura, talvez de grande parte dos adolescentes brasileiros. "Tirar o prazer" significa racionalizar ou regrar seus impulsos sexuais, considerando uma traição à sua virilidade; pois ser homem é "naturalmente" ter menos controle de seus impulsos sexuais e agressividade (PAIVA, 1991).

Apesar da mudança nas relações de gênero nas últimas décadas, alguns adolescentes ainda atribuem a responsabilidade da prevenção à mulher. Isso acontece porque as representações discursivas de que as mulheres são as únicas responsáveis pela regulação da fertilidade, da reprodução e da maternidade ainda perduram na sociedade. Assim, esses discursos continuam produzindo efeitos sobre as relações de gênero desiguais. No caso dos adolescentes, essas relações interferem de forma considerável na sexualidade e no entendimento que têm em relação à saúde reprodutiva, pois elas são estruturas presentes em seu contexto e responsáveis por socializações generificadas (YÉSPE; PINHEIRO, 2014).

De acordo com Aberastury (2003), outro fator importante e frequente na adolescência é o sentimento de onipotência. Este exercício de autoafirmação faz com que pensem ter imunidade contra tudo o que acontece ou possa acontecer em seu meio, expondo-se a riscos, perigos e ficando mais vulnerável em algumas situações.

\section{Considerações finais}

As interações afetivas são fundamentais para que se estabeleça a formação da identidade adolescente. É por meio delas que se experimentam, em um círculo mais amplo de pessoas, relações de companheirismo, responsabilidade consigo e com o outro, empatia e confiança. As trocas e experiências íntimas, com ou sem experiência sexual, são importantes para o desenvolvimento da vida sexual. A curiosidade, a atração sexual e o desejo se intensificam possibilitando a oportunidade de estabelecer vínculos de relacionamentos afetivos casuais, eventuais ou duradouros.

Os relacionamentos afetivos casuais e eventuais tomam forma na linguagem do adolescente com a relação sem compromisso "ficar" ou "pegar", não havendo vínculo pessoal ou mesmo um compromisso duradouro. É interessante observar que apesar da relação sem compromisso ser muito comum atualmente, esta forma de experimentação é carregada de preconceito não só entre os adultos, mas pelos próprios adolescentes. Há uma distinção sobre a variação de parcerias (tempo de espaçamento e lugar) para as garotas e para os rapazes.

O "ficar" e o "pegar" também representam uma atitude revolucionária perante a sexualidade. Os rapazes e as garotas "ficam" ou "pegam", o que permite uma sexualidade muito mais interessante. O desejo do adolescente é intenso, fluido e está em todo lugar. Estamos imersos em um processo de instalação de novos conceitos de amor e sexo, em um mundo aterrorizado pelas DSTs. Ainda há poucas evidências sobre os impactos das relações sem compromisso que crescem cada vez mais com os adventos das tecnologias digitais e aplicativos de smartphone.

Há outro lado também que se revela na relação sem compromisso. Se, inicialmente, a relação sem compromisso é pensada como fruto de liberalismo ela, na verdade, é um remédio ao mal-estar que o liberalismo provoca. A despeito de se constituir para os adolescentes uma promiscuidade, a relação sem compromisso tem uma ética que é o adiamento de uma relação na qual o sujeito adolescente não poderia se posicionar, dadas às contingências de sua situação.

Também foi desvelada que a interdição da vivência da sexualidade ao sexo feminino está sendo lentamente vencida, pois o direito ao prazer afetivo/sexual aparece como uma conquista legítima e individual dessas garotas e compartilhada também 
pelos rapazes. Nem por isso desapareceram as diferenças no julgamento moral negativo das condutas das garotas em detrimento dos comportamentos dos rapazes.

O comportamento sexual humano, quando vivenciado de forma segura, em geral está ligado à alegria, ao prazer e à satisfação. Assim, entendemos que nas ações educativas, as informações devem ser corretas, precisas e principalmente atuais e contextualizadas, por isso este assunto não pode estar fora dos conteúdos destinados à educação em sexualidade para adolescentes e jovens, pois está relacionado ao sexo seguro, o que significa poder vivenciar a sexualidade de forma satisfatória, sem o temor de complicações que possam colocar em risco sua própria saúde e seu projeto de vida.

\section{Referências}

ABERASTURY, A; KNOBEL, M. Adolescência normal. Porto Alegre: Artmed, 2003.

BARDIN, I. Análise de conteúdo. Lisboa: Edições 70, 2010.

BADINTER, E. XY: La identidad masculina. Espanha: Alianza Editorial, 1993.

BOURDIEU, P. A dominação masculina. Rio de Janeiro: Bertrand Brasil, 2011.

BORGES, A. L. V; NAKAMURA, E. Normas sociais de iniciação sexual entre adolescentes e relação de gênero. Rev Latino-am Enfermagem, v. 17, n.1, jan.-fev. 2009. Disponível em: <http://www. scielo.br/scielo.php?script $=$ sci_arttext\&pid $=$ S0104$-11692009000100015 \&$ lng $=$ pt\&nrm =iso\&tlng = pt>. Acesso em: 24 fev. 2016.

BRASIL. Conselho Nacional de Saúde. Resolução 466/12. Brasília, Diário Oficial da União, n. 12, Seção 1, p. 59, 2013.

BRETAS, J. R. S.; MUROYA, R. L.; GOELLNER, M. B. Mudanças corporais na adolescência. In: BORGES, ALV; FUJIMORI E. (ORG). Enfermagem e a saúde do adolescente na atenção básica. Barueri: Manole, 2009. p. 82-115.

BRÊTAS, J. R. S; OHARA, C. V. S; JARDIM, D. P; JUNIOR, W. A; OLIVEIRA, J. R. Aspectos da sexualidade na adolescência. Ciência \& saúde coletiva, v. 16, n. 7, p. 3221-3228, 2011.
BRÊTAS, J. R. S; MORENO, R. S; EUGENIO, D. S.; SALA, D. C. P.; VIEIRA, T. F.; BRUNO, P. R. Os rituais de passagem segundo adolescentes. Acta Paul. Enferm., v. 21, n. 3, p. 404-411, 2008.

CASTRO, M. G; ABRAMOVAY, M; SILVA, L. B. Juventudes e sexualidades. Brasília (DF): Unesco, 2004.

CONNELL, R. W. Políticas da masculinidade. Educação e Realidade, 20 (2): 185-206, 1995.

DE JESUS, J.S.O. Ficar ou namorar: um dilema juvenil. Psicologia, São Paulo, v. 6, n. 1, p.67-73, jun. 2005.Disponível em <http://pepsic.bvsalud. org/scielo. php? script $=$ sci arttext\&pid $=$ S1676$-73142005000100009 \& \mathrm{lng}=\mathrm{pt} \& \mathrm{nrm}=\mathrm{iso}>$. Acesso em: 12 nov. 2016.

FOUCAULT, M. História da sexualidade I: vontade de saber. São Paulo: Paz e Terra, 2014.

HEILBORN, M. L. Sexualidade: o olhar das ciências sociais. Rio de Janeiro: Zahar Editores, 2006.

LAMAS, M. Gênero: os conflitos e desafios do novo paradigma. Proposta, v. $84 / 85$, p. 13-25, 2000.

OLIVEIRA, D. C; GOMES, A. M. T; MARQUES, S. C. "Pegar", "ficar" e "namorar": representações sociais de relacionamentos entre adolescentes. Rev Bras Enferm., v. 60, n. 5, p. 497-502, 2007.

PAIVA, V. Sexualidade e gênero num trabalho com adolescentes para prevenção do HIV/AIDS. In: PARKER, R. $A$ aids no Brasil. Rio de Janeiro: ABIA/IMS/ Uerj, 1991.

SOUZA, V. F. F; NUNES, M. L. S; MACHADO, C. J. S. Ficar é: um código de relacionamento entre adolescentes. Caderno Espaço Feminino; v. 25, n. 2, p. 1981-3082, 2012.

YÉPEZ, M. A. T.; PINHEIRO, V. S. Socialização de gênero e adolescência. Estudos Feministas, v. 13, n. 1, p. 216, 2005. 